\title{
LA PERSECUCIÓN DE LAS ACTIVIDADES MÁGICAS POR EL TRIBUNAL INQUISITORIAL DE LIMA, SIGLO XVIII
}

\author{
THE PERSECUTION OF MAGIC BY THE INQUISITORIAL COURT LIMA, \\ IN THE EIGHTEENTH CENTURY
}

\author{
Natalia Urra Jaque*
}

\begin{abstract}
En el siguiente texto conoceremos y analizaremos uno de los procesos inquisitoriales desarrollados en la ciudad de Lima durante el siglo XVIII contra el delito de superstición; por medio de él reconstruiremos los métodos judiciales empleados por el Santo Oficio y, al mismo tiempo, las etapas procesales que debía enfrentar la persona acusada de sortílega, bruja, hechicera o curandera. Los detalles exhaustivos del juicio contra Paula Molina nos ejemplificarán, por un lado, el modo de operar de la Inquisición y su percepción sobre las actividades mágicas y, por otro, la realidad que dichos procesos simbolizaban para la sociedad virreinal peruana.

Palabras clave: Inquisición, actividades mágicas, herejías, persecución.
\end{abstract}

Through the following text, we will know and analyze one of the inquisitorial processes developed in the city of Lima during the 18th century against the crime of superstition; by means of it, we will reconstruct the judicial methods used by the Santo Oficio, at the same time, the procedural stages that the marked person had to face of spell, witch, sorceress or healer. The exhaustive details of the judgment against Paula Molina, on the one hand, we will exemplify, , the way of operating of the Inquisition and his perception on the magic activities and, for other one, the reality that the above mentioned processes were symbolizing for the viceregal Peruvian colonial society.

Key words: Inquisition, magic activities, heresies, pursuit.

Los días 18 y 22 de febrero de 1778 se presentó ante el comisario inquisitorial de Lima Victoria Breña "[...] de casta quarterona, de estado casada, natural y vecina desta dicha ciudad de edad de 35 años [...]" (A.H.N. Inquisición 1649, exp. 13 imagen 1) para declarar en contra de Paula Molina " [...] conocida por la Pan y Queso de oficio Pescadora y de edad de más de 60 años [...]" (A.H.N. Inquisición 1649, exp. 13 imagen 1); pues aseguraba que esta

"[...] queria darle fortuna y $[\ldots]$ un remedio con el qual toda suerte de hombres irian tras della, y la llenarian de plata: $\mathrm{Y}$ llevada mas de curiosidad que de codicia acepto la propuesta no sin recelo porque la dicha Paula tenia fama de Bruja en aquel distrito y auna mujer de su confianza [...] encargo le cogiese tales y tales yerbas, y que al cogerlas mentase alos Demonios por sus nombres diciendole una retaila dellos [...]" (A.H.N. Inquisición 1649, exp. 13 imagen 1-2).
Anteriormente, en 1766, se había presentado Valeriana Mogollon, quien también denunció a Paula ante el comisario inquisitorial por realizar actividades similares, es decir, utilización de hierbas e invocación a los demonios; ambas testigos, por tanto, concordaban en la fama de bruja de la acusada $\mathrm{y}$, sobre todo, en la instrumentalización de objetos cuyos simbolismos representaban una unión con Satanás. Paula, sin embargo, se retractó de todas sus actividades y conocimientos, reconociendo ante el tribunal inquisitorial que solo los utilizó para engañar y así ganar dinero, pues confesó no haber

“[...] hereticado ni apostatado de nuestra Santa Fee Catholica ni tenido pacto expreso con el Demonio [...] y que por ser amiga de mujeres $[\ldots]$ las engañaba executando lo que tenia confesado: que no havia creido que sus laboratorios fuesen capas de dar fortuna a las mujeres para que los hombres las quisiesen y que los uso a instancia de ellas [...]" (A.H.N. Inquisición 1649, exp. 13 imagen 25).

* Universidad Andrés Bello, Facultad de Humanidades y Educación, Departamento de Artes y Humanidades, Santiago de Chile. Correo electrónico: natalia.urra@unab.cl 
Los inquisidores, por su parte, comenzaron un proceso contra ella en la que doce testigos explicaron y describieron las diversas prácticas realizadas por Paula; la mayoría de los relatos coincidían en el uso de instrumentos y objetos invocando al demonio y, por supuesto, en el desconocimiento total de la acusada respecto de la doctrina cristiana, pues aseguraban que esta renegaba de Dios y de sus Santos constantemente y que, incluso, pedía no nombrarlos cuando ejecutaba sus actividades, pues -según ella- así serían más efectivos (A.H.N. Inquisición 1649, exp. 13 imagen 1-25).

Durante el siglo XVIII también se procesaron a otras treinta y siete mujeres ${ }^{1}$ por este mismo tipo de prácticas, por ende, el proceso inquisitorial contra Paula no fue desconocido ni extraño para la sociedad virreinal peruana, ya que desde sus inicios el Santo Oficio limeño se propuso erradicar todas aquellas actividades y costumbres que desestabilizaran el orden social y, sobre todo, amenazaran la armonía religiosa (Millar 1998: 230-233). Las prácticas mágicas, por tanto, fueron perseguidas y, al mismo tiempo, sancionadas por las leyes eclesiásticas y civiles; tanto unas como otras las catalogaron de peligrosas y les atribuyeron una serie de características y cualidades negativas con el propósito de eliminarlas, pues en el contexto virreinal no solo representaban una alianza con el demonio, sino también la supervivencia de los antiguos rituales religiosos precolombinos y africanos, por consiguiente, doblemente dañinas (Mannarelli 1998: 32-36).

Ahora bien, en esta oportunidad conoceremos, analizaremos y comentaremos uno de los procesos inquisitoriales desarrollados en la Lima colonial, pues creemos que con el relato exhaustivo del juicio contra Paula Molina es posible reconstruir un período histórico en el que los métodos represivos utilizados por la Inquisición eran esenciales para mantener el orden establecido, pues al perseguir estas actividades los inquisidores intentaban homogenizar religiosa y culturalmente a la sociedad, por consiguiente, respaldaban y mantenían el sistema político y jerárquico propio de las sociedades coloniales hispanoamericanas.

\section{Tribunales inquisitoriales y el delito de superstición ${ }^{2}$}

Para analizar el proceso contra Paula primero que todo debemos aclarar la postura del Santo Oficio respecto de las actividades mágicas y, paralelamente, conocer las percepciones y métodos empleados contra tales herejías; en primer lugar, corresponde enfatizar la postura ambigua de los tribunales inquisitoriales, es decir, por un lado fueron "el primer aparato represivo que afirmó la impotencia de las brujas adecuando sus sanciones a ello" (Guilhem, 1984: 199) y, por otro, la primera institución "ilustrada y progresista" (Guilhem, 1984: 199) que en palabras de Henry Charles Lea "[...] mantuvo una postura escéptica encomiable en comparación con la irracional ferocidad que prevalecía en otros lugares" (Tausiet, 2004: 119). En este caso, no tuvo una política concreta, incluso el mismo ambiente ideológico del período en estudio contribuyó a ello; los escépticos, por ejemplo, creían que estos actos eran consecuencia de fantasías irracionales y, por su parte, los creyentes los vincularon a la presencia indiscutible del demonio. Así pues, los inquisidores no prestaron un interés mayor a este tipo de delitos, pues los consideraron "[...] una pérdida del tiempo y de las energías necesarias para otras cuestiones más acuciantes" (Tausiet, 2004: 68). El número de víctimas, por tanto, fue reducido en comparación a las de otras justicias y, sobre todo, a las de otros lugares (Levack, 1995: 47-49).

No obstante, en el contexto virreinal peruano la importancia dada a los sortílegos y su eliminación fue una preocupación constante; René Millar realizó una investigación en la que divide las actividades judiciales contra los delitos mágicos en cuatro etapas. Una primera que abarca desde su fundación en 1569 hasta finales de 1580, cuyas cifras numéricas son reducidas y caracterizadas por un desconocimiento total hacia tales actividades, además, el mismo historiador nos advierte que en la lectura del primer edicto de fe de 29 de enero de 1570 no se incluyeron las actividades mágicas como delitos a denunciar (Millar, 1998: 232).

Una segunda etapa donde las cifras aumentan, cuyo período comprende entre finales del siglo XVI y fines del siglo XVII, sobre todo entre los años 1590 y 1610 y, posteriormente, entre 1630 a 1660 y 1670. Para René Millar esto es consecuencia de las nuevas directrices adoptadas por los tribunales, es decir, "el aumento de la actividad represiva contra la hechicería durante el siglo XVII se enmarca en una política general de la Inquisición al respecto, que tiene su punto de partida en Roma, con la bula del Papa Sixto V de 1586" (Millar, 1998:232), a lo que se sumó diez años más tarde (1596) el Breve de Clemente VIII, cuyo documento 
permitía al inquisidor general conocer todos los motivos sospechosos de herejía, y una carta del consejo de la suprema con fecha 12 de mayo de 1615 en la que se ordenaba a todos los tribunales inquisitoriales actuar escrupulosamente contra los delitos de hechicería. Dos años después, en 1617, se envió a todos los tribunales la bula traducida al castellano, con la intención de que fuese publicada mediante edictos en iglesias y monasterios, "los inquisidores de Lima dejaron constancia de haberla recibido, comentando la importancia que tenía para estas regiones en donde había muchas supersticiones y hechicerías, por lo que resultaba conveniente que el Santo Oficio conociera de ellas" (Millar, 1998: 232); toda esta política terminó en la cuaresma limeña de 1629 con la publicación de un edicto especial contra los ejecutores de las actividades mágicas en el que se advertía a toda la población, con pena de excomunión, a denunciar a tales personas.

La tercera etapa desarrollada en la primera mitad del siglo XVIII concentra el grueso de sus actividades en los delitos de hechicería y bigamia, la razón se debe a que algunas herejías no eran de mayor importancia para los inquisidores limeños, ya que por un lado escaseaban y, por otro, habían sido eliminadas con éxito de estas tierras, sin embargo, prestaron mayor importancia a aquellas prácticas arraigadas en la población como las distintas formas de superstición, cuestión plasmada en las instrucciones del inquisidor general y la Suprema de 1707 al Obispo de Quito, donde se le pedía enfrentarse con ahínco a la hechicería. La última etapa concuerda con el ocaso del Santo Oficio, pues disminuyen notablemente las causas de fe, pero sí aumentan los delitos de bigamia y los cometidos por el clero (solicitación) (Millar, 1998: 233).

Por lo tanto, el Tribunal de Lima condenó las actividades mágicas durante toda su existencia, ya que muchos vacíos dogmáticos y los hábitos relajados de los fieles católicos hacían temer a los inquisidores la posible inserción de herejías, por ende, su labor junto al resto de instituciones religiosas fue la de adoctrinar a la población católica, sobre todo, en tierras americanas, cuya especial estructura social compuesta por indígenas, negros, mestizos, mulatos, zambos, etc. Estaba propensa a creer en las supersticiones. Sin ir más lejos, nuestra protagonista era una mujer de casta zamba.

\section{El proceso inquisitorial contra Paula Molina}

Durante el período histórico que estudiamos y analizamos el poder era considerado propiedad de Dios, por ende, los únicos capacitados para ejercerlo eran los inquisidores o los hombres de Iglesia (Tausiet, 2004: 64-65); estos estaban convencidos de tener en sus manos la verdad absoluta y ser los únicos capacitados para condenar las herejías. En la práctica, sin embargo, la cuestión fue mucho más compleja, pues algunos distritos inquisitoriales eran más grandes que otros ${ }^{3} \mathrm{y}$, en este caso, la figura de los inquisidores no siempre era visible, por tanto, el sistema de visitas se transformó en un instrumento primordial para recordarles a todos la presencia del Santo Oficio y, por consiguiente, socorrer las denuncias que la lejanía de los tribunales obstaculizaba.

Las visitas debían efectuarse por lo menos una vez al año, aunque la gran mayoría de los inquisidores las retrasaba o simplemente las esquivaba, no obstante, la forma cotidiana de desarrollarlas consistía en la llegada de un inquisidor, un notario del secreto, un aguacil y un nuncio a los distintos lugares de la jurisdicción del tribunal; estos debían mostrar sus credenciales a las autoridades civiles y religiosas para luego leer un pregón cuya finalidad era convocar a todas las personas a escuchar la lectura de un edicto, en que se daban a conocer las distintas herejías y, además, se invitaba a denunciarlas o confesarlas según fueran de otros o propias. Los primeros edictos fueron llamados De Gracia, pues daban la opción de confesar las transgresiones en un período limitado de treinta a cuarenta días para luego reconciliarse con la Iglesia sin sufrir condenas; la idea, no obstante, era educar a la población con las nociones de herejía y, por supuesto, con los nuevos métodos de justicia. Posteriormente, con el afianzamiento del Santo Oficio los inquisidores ya no los llamaron De Gracia sino De Fe, pues cada día incorporaban herejías nuevas y no contemplaban en ellos ningún tipo de absolución.

Por otra parte, el arribo del inquisidor y su séquito a un determinado lugar significaba modificar la cotidianeidad de sus habitantes, pues su visita no solo implicaba erradicar las herejías, sino también remover antiguas disputas entre sus lugareños, ya que mediante el uso de la confesión se podía acusar y culpar a los enemigos para así librarse de ellos; aunque en algunos casos las acusaciones no necesariamente eran producto de odios o rencillas, pues era tal el examen de 
conciencia que muchos confesaban sus culpas solo por temor al castigo divino. En este caso, el miedo se transformó en una de las principales técnicas utilizadas por la Inquisición para ampliar su poder, es decir, "la pedagogía del miedo" se convirtió en la armadura contra la herejía, ya que "la finalidad primera de los procesos y de la condena [...] no es salvar el alma del acusado sino procurar el bien público y aterrorizar a la gente (ut alii terreantur)". (Bennassar 1984: 94).

Algunas de las testigos en el juicio contra Paula Molina, por ejemplo, declaraban sin ser llamadas, pues aseguraban que nuestra protagonista era una bruja; otras, en cambio, lo hacían por petición de los inquisidores, no obstante, ambos discursos coincidían en tal fama. La testigo María Andrea de Sosa aseguraba que esta "[...] la dijo comprase una Piedra Yman, y que quando usase del matrimonio con su marido cogiese el semen, y lo embolbiese en un pañuelo con la referida Piedra y se lo embiase: Que dicha Paula tenia fama de bruja, y que en el Callao todos la conocían por tal" (A.H.N. Inquisición 1649, exp. 13 imagen 4). Andrea Trigos, sin embargo, fue llamada a declarar por los inquisidores; esta se presentó el 4 de abril de 1778 ante el comisario inquisitorial para relatarle que "conocia una zamba nombrada Paula [...]ala qual con motivo de vivir inmediata a ella en la Rancheria de la Playa la oia con frecuencia llamar a los Diablos y banagloriarse de que la tubiesen por bruja cuya [...] fama era corriente" (A.H.N. Inquisición 1649, exp. 13 imagen 5).

Ahora bien, para comenzar un proceso inquisitorial existían tres formas, las más comunes eran:

"[...] una acusación de parte (en la que el acusador debía probar lo que decía), [...] una delación o denuncia (efectuada a partir de sospechas suscitadas por el comportamiento del acusado, aunque el denunciante no aportase prueba alguna) o como resultado de una pesquisa. En este último caso el tribunal actuaba ex officio, es decir, por propia iniciativa" (Tausit, 2004: 90).

El proceso contra Paula comenzó con las confesiones o declaraciones de tres testigos; todas ellas eran mujeres y aseguraban hacerlo por voluntad propia, pues querían descargar su conciencia. Por ejemplo, la testigo anteriormente citada, de nombre
María Andrea de Sosa, se presentó voluntariamente ante el comisario inquisitorial los días 13 y 17 de abril de 1778 para ratificar que

“[...] por el mes de octubre del año proximo pasado fue al Callao y hablando con una zamba pescadora nombrada Paula [...] conocida por la Pan y Queso la refirio lo que padecía con su marido, y dicha Paula la dijo: yo conozco una mujer que le puede sanar desos trabajos; $y$ habiendo venido esta [...] al quarto dela denunciante encendió un zigarro, lo chupo, y bebió aguardiente y dijo ala declarante: yo lo conozco es mui hablador guarda silencio y llama al Diablo [...]" (A.H.N. Inquisición 1649, exp. 13 imagen 4).

El siguiente paso consistía en buscar la información necesaria que respaldara la acusación, podía ser dada por los mismos inquisidores o por comisarios que ayudaban a los tribunales, sobre todo, cuando los distritos eran muy extensos. Más tarde se realizaba la calificación por parte de teólogos expertos, cuyo examen era comprobar hasta qué punto los hechos revelados convertían en hereje a la denunciada; esta etapa, sin embargo, no siempre se consumaba, pues cuando era tal la convicción de herejía se pasaba automáticamente a la siguiente etapa o clamosa; en esta el procurador fiscal se adjudicaba el rol de acusador, pues llamaba formalmente a la denunciada y, además, redactaba una orden de prisión seguida de la confiscación de bienes, por tanto, la captura de la reo se hacía con un aguacil, un receptor y un escribano de secuestro, quien era el encargado de anotar los bienes de la reo y, al mismo tiempo, evitar que esta llevara objetos peligrosos a las cárceles. Paula, por ejemplo, fue detenida el 3 de agosto de 1778 por orden del secretario fiscal, quien "[...] vista la causa se boto a prisión [...] con embargo de sus bienes, y se libro el mandamiento, que se actuo en la persona, y no en aquellos por no tenerlos; y traída alas cárceles fue reclusa en ellas en el mismo mes y año con racion de pobre" (A.H.N. Inquisición 1649, exp. 13 imagen 10).

Las prisiones del Santo Oficio eran conocidas como cárceles secretas, en ellas los y las reos tenían prohibido las visitas de familiares y amigos, impidiéndoles toda comunicación con el exterior. Dentro de ellas tampoco podían mantener contacto con otras personas, aunque en algunas ocasiones las celdas 
eran ocupadas por más de una rea, no obstante, cuando esto sucedía se intentaba que fueran por diferentes delitos, pues así los inquisidores evitaban posibles intercambios de información y, por tanto, la conversión mediante el aislamiento. Esto último generaba alteraciones psicológicas muy importantes en las reos, ya que todo apuntaba a obtener una declaración contraria a lo que la acusada pensaba, es decir, mediante estos cambios de personalidad los inquisidores obtenían confesiones acordes a sus intereses y, según los criterios de la nueva justicia, la confesión era la prueba por excelencia para comprobar la herejía (Tausiet, 2004:88-92). Paula, por ejemplo, dijo confesar " [...] la verdad enteramente quanto grababa su conciencia deseosa de que la divina magestad la perdonase, y este tribunal la mirase con piedad" (A.H.N. Inquisición 1649, exp. 13 imagen 24-25).

La siguiente etapa del proceso inquisitorial era la audiencia de la reo; estas se desarrollaban en distintas sesiones y tenían por finalidad conocer los datos personales del prisionero, es decir, el estado civil, la profesión y el lugar de residencia, además, se le preguntaba por su nivel cultural y religioso. La primera audiencia de Paula fue ejecutada el 5 de septiembre de 1778; en ella,

\section{"[...] dijo llamarse Paula Molina de casta zamba natural desta ciudad de edad de 60 de estado casada, de exercicio pescadora, que bino presa la noche del dia quatro de agosto proximo pasado. Tomasele la ge- nealogia conforme a la Castilla de la que nada resulto sobre ser [...] infecta ni de penitenciados, y manisfesto estar media- namente instruida en la Doctrina Cristiana, en quanto a saber las oraciones rememoria; aun que lo estaba bien en los misterios de nuestra sagrada religión. Que no sabia leer ni escribir [...]" (A.H.N. Inquisición 1649, exp. 13 imagen 18).}

La cantidad de veces que podían efectuarse dependía de los inquisidores encargados del proceso, aunque por norma general la prisionera podía solicitarla cuantas veces quisiera; en el caso de Paula Molina, estas se dividieron en tres Ordinarias, una De Acusación, dos De Comunicación de la Acusación, dos De Publicación, una De Acusación de Publicación y una De Definición. En todas ellas la prisionera agregó información relevante o fundamental para el desarrollo pertinente del juicio. No obstante, el 7 de septiembre de 1778 solo ratificó "[...] tener declarada enteramente la verdad y que no se sentía culpada en otra cosa e imploraba la piedad de este Santo Oficio" (A.H.N. Inquisición 1649, exp. 13 imagen 23).

Sin embargo, cuando la prisionera pedía expresar su delito voluntariamente se la recibía en confesión, si por el contrario esto no sucedía se pasaba a la siguiente etapa: la acusación formal por parte del fiscal. Este documento era un extracto de las declaraciones de los testigos y ayudantes del proceso, también solía ser uno de los más importantes, pues era el que se le leía a la reo con la intención de que afirmara y respondiera todos los cargos que se le atribuían, quien además se asesoraba por un abogado capacitado y autorizado para ejercer en los tribunales del Santo Oficio, pues siempre era uno de los dos o tres eruditos que trabajaban en ellos. No obstante, el objetivo principal del abogado no era la defensa de la reo sino buscar su culpabilidad o inocencia. En la Primera Audiencia de Comunicación de la Acusación, el abogado Mariano Narciso de Aragón, doctor en teología,
“[...] la aconsejo [...] para descargo de su conciencia dijese verdad y si era culpada pedir misericordia a que la reo aseguro tenerla dicha en sus confesiones aque se referia y negaba lo demás contenido en dicha acusacion y pidio se le tratase piadosamente por lo que tenia confesada [...]" (A.H.N. Inquisición 1649, exp. 13 imagen 29).

En la fase probatoria se reunían el procurador fiscal y la acusada para corroborar y exigir las pruebas pertinentes a la acusación, cuestión que para el delito de superstición era muy difícil de demostrar, por ende, las declaraciones de los testigos se transformaban en la prueba por excelencia para confirmar la culpabilidad de los acusados. Estas declaraciones, sin embargo, eran desarrolladas mucho antes, solo que en la etapa conocida como ratificación de los testigos, estos las revalidaban bajo juramento y cuando alguna de ellas era contradictoria el inquisidor decidía cuál se ajustaba más a la verdad, castigando con prisión y tormento al o la declarante. La cantidad de testigos llamados a declarar no era un tema a debatir, pues bastaba con dos para comenzar un proceso contra alguien, aunque 
se evitaba que estos fueran enemigos, familiares, menores de edad, herejes, etcétera.

Las testificaciones que éstos hacían no eran del todo espontáneas, pues se limitaban a responder un cuestionario cuya publicación, de acuerdo con el derecho común, debía indicar sus nombres, aunque el secreto inquisitorial lo prohibía, pues así los inquisidores evitaban represalias o venganzas (Tausiet, 2004:92-94). Además, la defensa del acusado podía utilizarlas de dos formas: una por aportación de abonos y otra por aportación de tachas, es decir, en el primer caso los testigos estaban a favor del reo y en el segundo se demostraba que no eran fiables.

En el proceso contra Paula los testigos dieron a conocer su nombre, su raza, la ciudad en la que vivían, su estado civil y edad y, por supuesto, los motivos para considerar de hereje a la supuesta sortílega; sin embargo, en la publicación de los testimonios presentada por el abogado de la acusada los datos personales de estos no se muestran, pues solo se limita a presentar si el testimonio dado por el o la testigo es concordante con la versión de la prisionera, por ejemplo: Valeriana Mogollon, primera testigo, dice ser:

"de casta negra, natural de esta ciudad, de estado casada, de edad de quarenta y cinco años y [...] que Paula molina zamba la expreso en el camino del Callao, que llebaba una yerba llamada el tabaco, y se la había dado una mestiza serrana nombrada manuela, con el fin de que haciendo un menjunge de dicha yerba con aguardiente la solviese con las narices, y hecho esto la siguiese un hombre con quien tenia amistad ilícita" (A.H.N. Inquisición 1649, exp. 13 imagen 1).

Mientras que el abogado Mariano Narciso de Aragón solo publicó que "Al testigo primero, muger mayor jurada y ratificada ante el comisario de esta ciudad, en 18 y 22 de Abril de 1766 era cierto lo que deponia la testigo" (A.H.N. Inquisición 1649, exp. 13 imagen 30 ).

El procedimiento se daba por terminado cuando la prisionera y el abogado fiscal dejaban de hacer peticiones para dar paso a la sentencia; no obstante, si la acusada se negaba a confesar el delito los inquisidores utilizaban el método de tortura. Este método, sin embargo, se aplicaba solo cuando las pruebas demostraban que la acusada era culpable y aún así este continuaba negándolo; por otra parte, las técnicas usadas fueron las más comunes y conocidas, es decir, la garrucha, el tormento del agua y el potro. Los mismos inquisidores pedían tener cuidado con el uso del tormento, pues tanto los manuales como las normas generales recomendaban no excederse para así evitar la muerte del o la prisionera ${ }^{4}$.

En nuestra investigación archivística ningún documento nos explica claramente si se empleó algún método de tortura contra las reos, pero sí de forma implícita se menciona que María Rosalía, procesada 1734, "contradecía el tormento" (A.H.N. Inquisición, legajo 5346, $\mathrm{n}^{\circ}$ 2, folios 35-47). Además, el historiador René Millar asegura que los inquisidores limeños no aplicaban tormento a las acusadas por supersticiosas, "ni siquiera cuando las testificaciones coincidían en la acusación de invocar reiteradamente al demonio" (Millar, 1998:250), pues de las 155 causas que él estudió solo encontró 2 casos en los que se mencionó el uso de la tortura y uno de ellos es el de María Flores procesada en 1709 (A.H.N. Inquisición, legajo 5345, $\mathrm{n}^{\circ}$ 4, folios 109-111).

No obstante, "muchas personas acusadas de brujería confesaron su participación en los hechos para evitar males mayores, porque reconociéndose culpables evitaban la tortura y obtenían la libertad; $\mathrm{y}$ otros porque se sienten obligados a afirmar lo que les dicen" (Martín 2000: 86), además, debemos tener presente que la tortura es el método utilizado para causar dolor físico, moral y psicológico y, muchas veces, el temor al dolor es una herramienta tan eficaz que la expresión "ha confesado por su propia voluntad disimulaba una triste y terrible realidad" (Martín 2000: 77), pues bastaba con privar de libertad a la reo bajo una cierta inhospitalidad y obligarla a confesar un crimen no cometido para hablar de tortura. Paula, por ejemplo, contradijo el tormento; pues " $[\ldots]$ havia confesado $[\ldots]$ ampliamente sus delitos y pidio sele viese con misericordia" (A.H.N. Inquisición 1649, exp. 13 imagen 40).

Por otra parte, la condena sufrida por nuestra protagonista evidencia claramente un tipo de vejamen misógino que se suma a los métodos de tortura ya mencionados como, por ejemplo, el salir por las calles públicas y más recurridas de la ciudad desnudas de la cintura hacia arriba ${ }^{5}$. Así pues, fue el caso de Paula, quien fue condenada a salir " [...] desnuda dela cinta arriba enbestia de albanda por las calles publicas y acostumbradas de esta ciudad y [...] relevada de azotes por su avanzada edad [...]" (A.H.N. Inquisición 1649, exp. 13 imagen 43). 
En este sentido, la tortura era implícita y amparada por normas patriarcales; El Santo Oficio, por tanto:

“[...] participaba en la construcción de identidad y de las definiciones normativas y expectativas del género sexual. ¿Dónde mejor llevar a cabo esa estrategia en que se le da la palabra a una mujer, para que enuncie las frases que ya le tenían preparadas, bajo circunstancias cuyo propósito es controlar su cuerpo para así poder controlar su discurso?" (Schlau, 2008: 7).

El proceso, sin embargo, debía ser revisado nuevamente por los inquisidores, el ordinario del lugar y los consultores del Santo Oficio ${ }^{6}$ antes de pronunciarse la sentencia final, cuestión que con los años se eliminó, ya que las sentencias fueron traspasadas directamente a la Suprema; esta debía ser escrita con todos los relatos erróneos de la prisionera y, por supuesto, sin dar a conocer los nombres de los y las testigos ni mucho menos las circunstancias que hicieran deducir sus nombres, pues aún en esta etapa seguía manteniéndose el secreto inquisitorial.

Las sentencias reunían en una, tres tipos de condenas; es decir, una condena espiritual, una condena corporal y una condena financiera. En el primer caso se hacía referencia a las abjuraciones, reconciliaciones o distintas penitencias; en el segundo caso a las penas por destierro, relajación, latigazos galeras, etc., y en el tercero a la confiscación de bienes. La abjuración, sin embargo, era la pena más común, pues por medio de ella se intentaba eliminar las sospechas de herejías que perseguían a la reo y, además, podían ser de Levi, Vehementi o Violenta según la gravedad del crimen (Tausiet, 2004: 95-97). La mayoría de las prisioneras abjuraban en público o en privado pese a que no siempre se les comprobaba su delito; las más comunes, al respecto, eran las vehementemente sospechosas y violentamente sospechosas, ya que en palabras de Michel Foucault,

"La demostración en materia penal no obedece a un sistema dualista-verdadero o falso-, sino a un principio de gradación continua: un grado obtenido en la demostración formaba ya un grado de culpabilidad e implicaba, por consiguiente, un grado de castigo. El sospechoso, como tal, merecía siempre determinado castigo: no se podía ser inocentemente objeto de una sospecha" (Foucault, 1996:48).

Paula, por ejemplo, fue acusada de "[...] sortilegio formal con sospecha de pacto expreso, fundada en la invocación a los Demonios en la linea de lebi, mas sospechosa en la fee" (A.H.N. Inquisición 1649, exp. 13 imagen 8).

Ahora bien, la ceremonia de la abjuración cumplía ciertos protocolos, sobre todo cuando era solemne; en primer lugar, el inquisidor daba un sermón y luego la prisionera vestida con el sambenito (traje penitencial caracterizado por tener una cruz delante y atrás) se colocaba en un lugar visible para todos los feligreses y así abjurar de todas las culpas que se le acusaban, no obstante, debía cumplir algunas penitencias para ser aceptada nuevamente en el seno de la Iglesia. Algunas de ellas eran llevar el sambenito, pagar una multa aproximada de cien ducados, ser desterrada temporalmente, sufrir de cien a doscientos azotes, ser encarcelada o ser destinada a galeras.

En el caso de Paula, su condena fue ejecutada el 20 de mayo de 1779 en un Auto Particular de fe; en él se le leyó su sentencia con mérito y se acordó que esta fuese
"[...] absuelta ad cautelam, gravemente reprehendida adbertida y comminada, [...] reclusa por espacio de cinco años en la Casa de Amparadas dela Purissima Concepcion de esta otra ciudad a servir en el lugar que llaman Penitencia en los exercicios a que la destinase la superiora: Confesase y comulgase en las tres Pascuas de Resureccion, Espiritu Santo y Navidad, de dicho tiempo y en el resase una parte del Rosario a la Santisima Virgen de rodillas [...]" (A.H.N. Inquisición 1649, exp. 13 imagen 42-43).

No obstante, cuando la sospecha se convertía en herejía formal la reo podía ser acogida a reconciliación, pero siempre y cuando se le considerase hereje confidente arrepentido. Igualmente esto conllevaba a ser absuelta y readmitida nuevamente en el seno de la Iglesia mediante la abjuración, solo que las sanciones eran mucho más duras que las anteriores, es decir, en este caso las penas, además de llevar 
el sambenito y sufrir cárceles, iban acompañadas de confiscación de bienes muebles y raíces y la imposibilidad de disfrutar de honores, dignidades y oficios (Tausiet, 2004:99). Nuestra protagonista, sin embargo, no sufrió tal condena, pues debido al nivel precario de su economía era imposible confiscarle bienes, asimismo, ella confesó practicar las actividades mágicas para subsanar esta carencia; en su primera audiencia, por ejemplo, celebrada el 5 de septiembre de 1778, confesó

\begin{abstract}
"enteramente la verdad pues su deseo era salbar su alma: que ni era bruja ni sabia formar hechizos, y que por engañar y zumbar a las personas que la solicitaban y luenar algunas reales que le daban, executo lo que ha declarado, y que se hallaba arrepentida esperando de este santo oficio que la mire con piedad en atención asu torpeza y algrave dolor que le asiste de sus excesos" (A.H.N. Inquisición 1649, exp. 13 imagen 22).
\end{abstract}

Si la prisionera acusada de hereje formal o vehementemente sospechosa cometía una vez más los mismos delitos se le consideraba relapso y, del mismo modo, que el hereje no arrepentido terminaba siendo relajada por el brazo secular; no obstante, la condena a muerte la desarrollaba la justicia seglar, pues el derecho canónico no permitía a ninguna institución eclesiástica ejecutar tal sentencia. La sanción máxima para este tipo de condenas era la muerte en la hoguera, aunque muchos arrepentidos eran estrangulados antes de ser conducidos a los estrados y otra gran cantidad moría en las mismas cárceles fruto de la inhospitalidad de ellas. En los procesos por brujería y hechicería fue muy común dar la absolución o suspender el caso, sobre todo, en los últimos años de la Inquisición.

Por otra parte, los encargados de desarrollar los procesos inquisitoriales se dividían en dos grupos: por un lado los oficiales y, por otro, los ministros. Los del primer grupo siempre eran remunerados por sus labores, mientras que los del segundo solían actuar voluntariamente y, en algunos casos, cobrar por algo en concreto. El grupo de los oficiales se dividía, a su vez, por orden jerárquico, es decir, a la cabeza estaban los inquisidores seguidos por el fiscal. Dentro de este mismo grupo también estaban los notarios del secreto, de secuestros y del juzgado; el receptor, el aguacil, el alcaide, el nuncio, el despensero, el médico, el cirujano, los capellanes y el portero. En el grupo de los no pagados económicamente estaban los calificadores y consultores.

No obstante, las jurisdicciones territoriales que abarcaba cada tribunal hacían insuficiente el aporte de los teólogos, pues algunos como el de Lima eran tan extensos que necesitaba de la ayuda de otras instituciones para controlar y vigilar a la población. En este caso fue indispensable la colaboración de las otras justicias y los mecanismos empleados por cada tribunal para hacer efectivos la resolución de los procesos; uno de estos era la colaboración directa de la población, ya que cualquiera podía y debía denunciar una supuesta herejía (Tausiet, 2004:100-101). Al mismo tiempo, los tribunales contaban con personas encargadas de vigilar los comportamientos humanos, entre ellos los comisarios; estos eran

"sacerdotes locales que esporádicamente actuaban para los diferentes tribunales, sobre todo en la fase instructora, ya que redactaban información de todo tipo, recibían las denuncias y las declaraciones de testigos e incluso podían detener a un reo sin esperar a la orden de prisión oficial" (Tausiet, 2004:102).

Junto a ellos también estaban los familiares, quienes eran colaboradores laicos encargados de escoltar a los inquisidores, denunciar las herejías $\mathrm{y}$ arrestar a los herejes.

Finalmente, es cuestionable el supuesto rechazo a la Inquisición, ya que si consideramos el apoyo y la gran ayuda que recibía por parte de la población y que sin ella jamás se hubiera proyectado como una institución capacitada para beneficiar a unos y perjudicar a otros, podríamos concluir que "el tribunal no fue un cuerpo impuesto tiránicamente, sino la expresión de los prejuicios sociales que prevalecían en el seno de la sociedad" (Kamen, 1979:191).

\section{Conclusiones}

Para concluir debemos - primero que todo- enfatizar la importancia dada por el tribunal inquisitorial limeño a la persecución de las actividades mágicas; si bien estas no fueron relevantes ni ocuparon un pedestal superior dentro de las herejías perseguidas por el Santo Oficio, en tierras hispanocoloniales se transformaron en uno de los delitos más graves y 
desestabilizadores, pues representaban costumbres, creencias y tradiciones propias de las sociedades precolombinas y esclavizadas, por ende, debían controlarlas y, sobre todo, erradicarlas, ya que así homogenizaban o, al menos, intentaban mantener el sistema jerárquico, propio de las colonias hispanoamericanas.

Su postura ambigua respecto de los delitos mágicos fue, sin embargo, consecuencia de la poca visibilidad de estos, pues comprobar un pacto o no con el demonio era subjetivo y no siempre palpable, por ello, la confesión se utilizó como el único instrumento válido y legítimo para comprobar tal herejía; aunque esta podía estar condicionada por los mismos interrogatorios que los inquisidores hacían.

Sus métodos y formas de proceder simbolizaban una estructura y organización única en su estilo, pues cada proceso cumplía una serie de etapas protocolares que conllevaban a la realización perfecta de sus juicios, era imposible, por tanto, librarse de una sentencia, pues cada una de las etapas que enfrentaba el o la acusada estaban estrictamente organizadas y repaldadas. Esto, a su vez, provocó el recelo popular o social, por ende, la visión negativa que, hasta hoy, se sigue manteniendo sobre ella, es decir, sus métodos secretos y ocultos no siempre fueron comprendidos por una sociedad cuya composición era mayoritariamente popular e iletrada.
Aunque también es cierto que gran parte de esta misma sociedad la apoyó y respaldó, pues veía en ella el instrumento capacitado para desentenderse de odios o rencillas con sus enemigos y, por supuesto, para mantener el orden público.

Nuestra protagonista, por ejemplo, representaba a esta sociedad de forma cabal, es decir, pertenecía a la sociedad de castas propia de la jerarquización político-administrativa hispanocolonial, era pobre $\mathrm{y}$, por supuesto, analfabeta; hacía uso de antiguas tradiciones o creencias para solventar su economía precaria, pues como ella misma confesaba era su forma de ganar dinero. Su figura en sí simbolizaba todo aquello que el tribunal quería erradicar o, en otras palabras, controlar. Por lo tanto, el proceso contra ella ejemplifica magistralmente las razones que poseían estos tribunales para perseguir las prácticas ajenas al orden establecido, es decir, condenándola a ella no solo se eliminan las actividades mágicas, también se interviene en la mentalidad popular y con ello en el actuar de la misma.

\section{Agradecimientos}

Me gustaría agradecer a los(as) evaluadores(as) anónimos(as) que leyeron, analizaron y corrigieron este artículo, ya que solo con su mirada crítica fue posible la aceptación y, posteriormente, la publicación del mismo.

\section{Referencias Citadas}

\section{Fuentes}

Archivo Histórico Nacional de Madrid (A.H.N.), Sección Inquisición, Procesos de Fe del Tribunal de Lima, legajos: 1649, expediente 13.

5345 , número 4.

5342 , número 2.

\section{Bibliografía}

Bennassar, B. (Compil.) 1984 Inquisición Española: Poder Político y Control Social. Editorial Crítica, Barcelona.

Foucault, M. 1996 Vigilar y Castigar. Editorial Siglo XXI, Madrid. Guilhem, C.

1984 La inquisición y la devaluación del verbo femenino, en Inquisición española: Poder político y control social, compilado por Bennasar, B., Editorial Crítica, Barcelona. Guibovich Pérez, Pedro

1998 En defensa de Dios. Estudios y documentos sobre la Inquisición en el Perú. Ediciones del Congreso del Perú, Lima.
Kamen, $\mathrm{H}$.

1979 La inquisición española. Editorial Crítica, Barcelona.

Levack, B.

1995 La Caza de Brujas en la Europa Moderna. Editorial Alianza, Madrid.

Mannarelli, M.

1998 Hechiceras, Beatas y Expósitas. Mujeres y Poder Inquisitorial en Lima. Ediciones del Congreso del Perú, Lima.

Martín, R.

2002 Magia e Inquisición en el Antiguo Reino de Granada. Editorial Arguval, Málaga.

Millar, R.

1998 Inquisición y sociedad en el Virreinato Peruano. Ediciones Universidad Católica de Chile, Santiago de Chile.

Schlau, S.

2008 El Cuerpo Femenino y la Inquisición Colonial: dos Casos Ejemplares. Revista del Programa de Historia de América Latina. Vol. I, Primera Sección: Vitral Monográfico $N^{o} 1$.

Tausit, $\mathrm{M}$.

2004 Abracadabra Omnipotens. Magia Urbana en Zaragoza en la Edad Moderna. Editorial Siglo XXI, Madrid. 


\section{Notas}

1 AH.N. Inquisición de Lima. Procesos de Fe y Relaciones de Causas.

2 De acuerdo con lo investigado creemos necesario enfatizar y aclarar que el Santo Oficio español perseguía y castigaba los delitos de superstición, es decir, todas las creencias extrañas a la fe religiosa y contrarias a la razón (definición dada por la Real Academia de la Lengua española, vigésima segunda edición), por lo tanto, la brujería y la hechicería fueron encasilladas como tales junto al resto de cultos precristianos e idolátricos. En los archivos consultados comprobamos que la gran mayoría de mujeres condenadas por practicar actividades mágicas (hechizos y maleficios) fueron catalogadas como "supersticiosas" o "sortílegas", por ende, la expresión o término superstición era utilizado como sinónimo de brujería, hechicería, sortilegio e incluso idolatría.

3 El tribunal inquisitorial limeño, según René Millar, abarcaba los actuales Ecuador, Perú, Chile, Bolivia, Argentina, Uruguay y Paraguay, y hasta 1610 las actuales Colombia y Venezuela; por tanto, su jurisdicción comprendía aproximadamente tres millones de $\mathrm{km}^{2}$.

4 Los manuales autorizaban utilizar el tormento una vez por una hora.

5 A.H.N. Inquisición de Lima. Procesos de Fe y Relaciones de Causas.

6 Estos eran especialistas en teología, derecho canónico y derecho civil. 